\title{
¿LAS NORMAS DEROGADAS PUEDEN SER DECLARADAS INAPLICABLES POR INCONSTITUCIONALIDAD? COMENTARIO DEL FALLO ROL 1399-09 Y 1469-09 DEL TRIBUNAL CONSTITUCIONAL
}

\author{
Miriam Lorena HenríQUeZ Viñas*
}

\section{INTRODUCCIÓN}

El presente comentario jurisprudencial pretende analizar la sentencia del Tribunal Constitucional de 4 de noviembre de 2010, Roles $\mathrm{N}^{\circ}$ s 1399 09 y 1469-09, acumulados, originado en un recurso de inaplicabilidad por inconstitucionalidad del artículo $42 \mathrm{~N}^{\circ} 1$ inciso final de la Ley sobre Impuesto a la Renta.

Así, el objetivo central será razonar si procede declarar la inaplicabilidad por inconstitucionalidad de un precepto legal derogado por el legislador. Para la consecución del objetivo planteado, es que se considerarán las diferencias entre: a) Derogación e inconstitucionalidad; b) Existencia de la norma en el sistema jurídico y en el orden jurídico; c) Pertenencia y aplicabilidad. Luego, se examinarán tales diferencias en el marco del ordenamiento jurídico constitucional chileno, con énfasis en el control de constitucionalidad de los preceptos legales derogados, particularmente a la luz de la sentencia del Tribunal Constitucional, Roles $\mathrm{N}^{\circ}$ s 1399-09 y 1469-09 acumulados. Finalmente, se propondrán algunas conclusiones. No se abordarán, entonces, las razones o fundamentos esgrimidos por el Tribunal Constitucional para estimar que el artículo $42 \mathrm{No} 1$ inciso final de la Ley sobre Impuesto a la Renta es contrario a la Constitución.

\section{1) RESUMEN DEL FALlO}

Brevemente corresponde señalar que el Tribunal Constitucional en este caso conoció de los Roles $\mathrm{No}^{\text {s }} 1399$ y 1469, que corresponden a dos

Abogada, Universidad Nacional del Comahue (Argentina). Magíster en Derecho Público, Pontificia Universidad Católica de Chile (Chile). Doctora en Ciencias Jurídicas, Universidad de Santiago de Compostela (España). Profesora de Fuentes del Derecho, LLM Derecho, Pontificia Universidad Católica de Chile. Profesora de Sistema Interamericano de Protección de los Derechos, Magíster en Derecho Constitucional y Derechos Humanos, Centro de Estudios Constitucionales de la Universidad de Talca. Profesora Derecho Constitucional de las Universidades Alberto Hurtado, Andrés Bello y de Las Américas. Correo electrónico: miriamhenriquez@yahoo.es 
gestiones pendientes. La primera de ellas consiste en un recurso de casación en el fondo, del que conoce la Corte Suprema bajo el Rol N ${ }^{\circ} 4944-$ 2009, que el requirente interpuso en contra de la sentencia de segunda instancia dictada por la Corte de Apelaciones de Valparaíso, en los autos sobre recurso de apelación Rol No 238-2009, que confirmó la sentencia dictada por el Director Regional del Servicio de Impuestos Internos de Valparaíso, en la causa Rol No 12.111-2007, que rechazó la reclamación tributaria. La segunda gestión se refiere a los autos sobre reclamación tributaria, Rol No 10.354-2008, de los que conoce el Tribunal Tributario de Valparaíso.

La acción de inaplicabilidad fue interpuesta por don Adolfo Paúl Latorre, recurrente de casación y reclamante, quien cuestionó la constitucionalidad del inciso final del numeral primero del artículo 42 de la Ley sobre Impuesto a la Renta, que fue derogado expresamente por la Ley $\mathrm{N}^{\circ}$ 20.219 de 2007. Dicho precepto a pesar de estar derogado en diciembre de 2007 se continúa aplicando en su caso particular, toda vez que los giros que son objeto de los reclamos pendientes ante los mencionados tribunales corresponden a los años tributarios 2007 y 2008, es decir fueron emitidos por las rentas percibidas en los años 2006 y 2007. El recurrente fundó la acción en la conculcación del derecho a la igualdad ante la ley, del $19 \mathrm{~N}^{\circ} 2^{\circ}$ de la Constitución. Precisó que la asimilación del precepto que impugna importa que, a diferencia de otros profesionales independientes, los prácticos de puertos y canales autorizados no puedan acogerse al beneficio tributario que a aquellos les concede el artículo 50 bis de la Ley sobre Impuesto a la Renta.

En lo medular el fallo de 4 de noviembre resolvió que es posible declarar la inaplicabilidad por inconstitucionalidad de los preceptos legales derogados por el legislador. Esto en un fallo dividido de ocho votos contra dos.

El voto en contra de los Ministros Viera Gallo y Carmona, se inició con una advertencia previa que recuerda: "La mayoría del Tribunal Constitucional hasta la sentencia Rol 1452 (05.08.2010) consideraba que una norma derogada no era precepto legal (STC roles 978/2008; 1186/2008; 1230/2009; 1231/2009; 1232/2009); por lo mismo, no cabia a su respecto la inaplicabilidad, pues implicaba dar una eficacia ultractiva al precepto respectivo, cualidad que exigiria hallarse prevista expresamente (STC roles 1230/2009; 1231/2009; 1232/2009). Tal situación se traducia en dos causales de inadmisibilidad: de un lado, que no resultaba decisiva en la resolución del asunto controvertido (STC roles 760/2007; 843/2007; 978/2008). Del otro, carecia de fundamento plausible (STC roles 1230/2009; 1231/2009; 1232/2009). Dicha declaración la hizo tanto el Pleno (STC rol 843/2007) como sus Salas (STC roles 838/2007; 760/2007)”.

Es del caso que la sentencia en comento cambió de criterio en este punto, resolviendo en el Considerando Noveno: "Que, en opinión de es- 
tos sentenciadores, resulta perfectamente posible pronunciar un veredicto de inaplicabilidad por inconstitucionalidad respecto de un precepto legal que, a la fecha de la sentencia respectiva, se encuentre derogado por el legislador, siempre y cuando, como sucede en la especie, dicha norma hubiere estado en vigor en el momento en que se suscitó la situación jurídica regida por ella y deba ser aplicada por el juez de la gestión".

El Tribunal Constitucional completó tal argumento en el Considerando Décimo señalando que así lo dispone el artículo 93 No 6, esto es que el precepto impugnado de inconstitucionalidad debe resultar aplicable al caso concreto de que se trate, no exigiendo que el mismo se encuentre actualmente vigente.

De esta forma, el Tribunal Constitucional consideró que el constituyente previó la hipótesis de la ultraactividad de una disposición derogada, es decir, de aquellas normas que si bien no rigen respecto de situaciones fácticas que acontezcan en la actualidad, sí regían en el momento en que ocurrieron los hechos que se juzgan.

Finalmente resolvió que la disposición legal que se impugna en la acción de inaplicabilidad en comento tiene el carácter de precepto legal cuya aplicación resulta decisiva para la resolución de los asuntos que se encuentran pendientes ante los tribunales de justicia, declarando la admisibilidad del recurso, para luego acogerlo.

\section{2) ANÁLISIS DE LA SENTENCIA}

Entrando al análisis de la sentencia, corresponde revisar las principales diferencias entre la derogación y la inconstitucionalidad.

La derogación está relacionada con la vigencia de la norma, mientras que la inconstitucionalidad es un tipo especial de invalidez, que implica la contravención de la Constitución.

El principio que determina la derogación es el cronológico, el cual resuelve verdaderos conflictos normativos diacrónicos entre normas válidas. Por su parte, los principios que hacen procedente la declaración de inconstitucionalidad son el jerárquico y de competencia, de los cuales no se derivan efectos derogatorios directos, a menos que los mismos se fijen expresamente por una norma superior, generalmente la Constitución.

La derogación es un fenómeno perfectamente regular, cuyo fundamento es responder al cambio en el sistema jurídico, ya sea para sustituir una norma por otra o para eliminar alguna norma perteneciente hasta ese momento al mismo. La inconstitucionalidad no busca innovar el sistema jurídico, sino que es el instrumento para conservarlo, defendiendo la supremacía constitucional.

La derogación es un acto legislativo, fruto de una decisión política; la declaración de inconstitucionalidad es un acto jurisdiccional, fruto 
de una "afirmación" del derecho". Así, quien deroga es el órgano con capacidad normativa, en este caso el legislador, quien lo hace con efectos generales y ex nunc. Sin embargo, la derogación tácita, es decir la derogación que se produce por la incompatibilidad entre normas producidas en distintos momentos temporales, requiere ser declarada. Tal declaración, generalmente emanada de un tribunal, importa un acto de interpretación al caso particular e implica limitar en el tiempo, sin anular, la aplicación de la norma derogada. La inconstitucionalidad requiere de un acto de interpretación de una autoridad jurisdiccional, ya sea judicial en los sistemas de control difuso, o de un órgano especializado como el Tribunal Constitucional en los sistemas concentrados.

Sin perjuicio de las diferencias apuntadas, corresponde afirmar que cada ordenamiento jurídico puede disponer sobre el régimen de invalidación de las normas y el régimen de eficacia de los actos declarativos de esa invalidez ${ }^{2}$. Esto es, quién tiene competencia para enjuiciar la validez de una norma y las condiciones en que se ejerce esa competencia-régimen de invalidación- y los efectos jurídicos que se atribuyen a los actos declarativos de invalidez-régimen de eficacia-, esto es efectos ex tunc o ex nunc.

Así, la decisión del constituyente en la reforma constitucional de 2005 fue -para el control represivo de constitucionalidad de los preceptos legales- la siguiente: a) La declaración de inaplicabilidad por inconstitucionalidad, del artículo 93 No 6 de la Constitución, corresponde al Tribunal Constitucional, quien si constata la inconstitucionalidad de la norma, tal declaración solo excluye su aplicabilidad para el caso concreto, manteniendo su vigencia y vocación indefinida de aplicabilidad a otros casos; b) La declaración de inconstitucionalidad, del artículo 93 No 7 de la Constitución, implica que constatada la inconstitucionalidad de la norma por el Tribunal Constitucional, la misma se invalida con efectos derogatorios, es decir no retroactivos. Como se observa, los efectos atribuidos por la Constitución a la declaración de inconstitucionalidad son diferentes según el control sea concreto o abstracto, el primero importa la inaplicabilidad de la norma; y el segundo la invalidez con efectos derogatorios de la misma.

Por otro lado, corresponde distinguir entre existencia en el sistema jurídico y existencia en el orden jurídico ${ }^{3}$. El sistema jurídico es el conjunto de normas vigentes en un momento determinado. El orden jurí-

Guastini, Riccardo (2001). "Cinco observaciones sobre validez y derogación”, Discusiones, No 2, p. 62.

2 Gascón, Marina (1997). "Sentido y alcance de algunas distinciones sobre la invalidez de las leyes", Doxa, No 20, p. 137.

3 Alchourrón, C, y Bulygin, E. (1991). Análisis lógico y Derecho, Madrid: Centro de Estudios Constitucionales, pp. 396 y ss. 
dico es la secuencia de los sistemas jurídicos que han existido en él. La derogación de una norma produce un cambio en el sistema jurídico por sustracción de normas, lo que significa que la norma derogada deja de existir, de tener vigencia, en el sistema correspondiente al momento posterior a la derogación, pero sigue existiendo en el ordenamiento jurídico al pertenecer a un sistema del mismo ${ }^{4}$. Ello explica que la norma pueda seguir siendo aplicada tras haber sido derogada, pues el conjunto de normas aplicables a un caso es una selección de normas vigentes en distintos sistemas, esto es, de normas vigentes en el sistema correspondiente al momento de tomar la decisión, pero también de normas que, a pesar de no estar vigentes en ese sistema, existen en el ordenamiento jurídico porque han pertenecido a un sistema anterior ${ }^{5}$.

Lo dicho se refuerza a su vez en la distinción propuesta entre pertenencia y aplicabilidad, que permite diferenciar entre el tiempo externo e interno de una norma ${ }^{6}$. El tiempo externo de una norma será el intervalo que va desde el momento en que es promulgada hasta el momento que es derogada. El tiempo interno de una norma será la secuencia de todos los momentos temporales en los que la norma es aplicable a algún caso. Así mientras el tiempo externo es una función de su pertenencia al sistema jurídico, el tiempo interno es una función de su aplicabilidad ${ }^{7}$. En muchas oportunidades el tiempo externo e interno no coinciden, así un juez en virtud de los criterios de aplicabilidad del sistema, debe aplicar normas ya derogadas, por cuanto aún pertenecen al orden jurídico.

\section{CONCLUSIÓN}

El cambio jurisprudencial en la sentencia que se analiza se centra en que los fallos anteriores al 4 de noviembre de 2010 requerían para la procedencia del recurso de inaplicabilidad por inconstitucionalidad de una norma vigente al momento de la presentación de la acción y hoy la exigencia es que la norma sea aplicable al caso concreto. Esto, en el correcto entendido de que la declaración de inaplicabilidad por inconstitucionalidad no se pronuncia sobre la pertenencia o vigencia de la norma al sistema jurídico, sino que enjuicia su (in)aplicabilidad en base a los efectos (in)constitucionales que pueda producir.

De esta forma, corresponde concluir, que una ley derogada -expresamente o tácitamente- por el legislador debe seguir aplicándose a las situaciones surgidas a su amparo antes de la derogación y aún no agotadas.

Gascón, Marina (1994). “Cuestiones sobre Derogación”, Doxa, No 15-16, p. 847. GASCÓN (1994) 847.

Alchourrón, C, y Bulygin, E. (1991), pp. 198 y ss.

Aguiló Regla, Josep (1992) “Derogación, rechazo y sistema jurídico”, Doxa, No 11, p. 275. 
En tal sentido, si es posible aplicar ultraactivamente una ley derogada es posible también declararla inaplicable.

\section{BIBLIOGRAFÍA}

- Aguiló Regla, Josep (1992) “Derogación, rechazo y sistema jurídico, Doxa, No 11, pp. 263-280.

- Alchourrón, C, y Bulygin, E. (1991). Análisis lógico y Derecho, Madrid: Centro de Estudios Constitucionales.

- Gascón, Marina (1994). "Cuestiones sobre Derogación”, Doxa, No 15-16, pp. 845-859.

- Gascón, Marina (1997). "Sentido y alcance de algunas distinciones sobre la invalidez de las leyes", Doxa, No 20, pp. 131-156.

- Guastini, Riccardo, (2001). "Cinco observaciones sobre validez y derogación”, Discusiones, No 2, pp. 59-63 